\title{
Implementation of the Recommendation to Vaccinate \\ Pregnant Women against Seasonal Influenza - \\ Vaccination Rates and Acceptance
}

\section{Umsetzung der Empfehlung zur Impfung schwangerer Frauen gegen saisonale Influenza - Quoten und Akzeptanz}

Authors

Sascha Baum ${ }^{1,4}$, Thomas Hitschold ${ }^{2}$, Anouck Becker ${ }^{3}$, Sigrun Smola ${ }^{3}$, Erich Solomayer ${ }^{4}$, Achim Rody ${ }^{1}$, Jürgen Rissland ${ }^{3}$

\section{Affiliations}

1 Klinik für Frauenheilkunde und Geburtshilfe des Universitätsklinikums Schleswig-Holstein Campus Lübeck, Lübeck, Germany

2 Frauenklinik des Klinikums Worms, Worms, Germany

3 Institut für Virologie, Universitätsklinikum des Saarlandes, Homburg/Saar, Germany

4 Klinik für Frauenheilkunde, Geburtshilfe und Reproduktionsmedizin des Universitätsklinikums des Saarlandes, Homburg/Saar, Germany

Key words

vaccination recommendations, vaccination against influenza, pregnancy, influencing factors, vaccination coverage

Schlüsselwörter

Impfempfehlung, Influenzaimpfung, Schwangerschaft,

Einflussfaktoren, Impfrate

$\begin{array}{ll}\text { received } & 4.1 .2017 \\ \text { revised } & 14.2 .2017 \\ \text { accepted } & 15.2 .2017\end{array}$

Bibliography

DOI http://dx.doi.org/10.1055/s-0043-103970

Geburtsh Frauenheilk 2017; 77: 340-351 ๔ Georg Thieme Verlag KG Stuttgart · New York | ISSN 0016-5751

Correspondence

Dr. Sascha Baum

UKSH Klinik für Frauenheilkunde und Geburtshilfe Campus Lübeck, Klinik für Frauenheilkunde und Geburtshilfe

Haus 12, Ratzeburger Allee 160, 23538 Lübeck, Germany sascha.baum@uksh.de

$\Theta$

Deutsche Version unter:

http://dx.doi.org/10.1055/s-0043-103970

\footnotetext{
ABSTRACT

Introduction In Germany vaccination recommendations are revised annually and published by the Standing Committee on Vaccination at the Robert Koch Institute (STIKO). In 2010 the vaccination recommendations were amended to include the proposal that pregnant women in the 2nd trimester of pregnancy and pregnant women with additional underlying disease in the 1 st trimester of pregnancy should be vac-
}

cinated against seasonal influenza. This paper reports on vaccination rates and the factors influencing them.

Method A cross-sectional study was carried out in two level 1 perinatal centers in two different German federal states (Saarland and Rhineland-Palatinate) during the influenza seasons of 2012/2013 and 2013/ 2014. A total of 253 pregnant women were included in the study. Pregnant women were interviewed using a standardized, pre-tested questionnaire and asked whether they were aware of the recommendation to vaccinate against seasonal influenza and about possible factors which might influence their decision to be vaccinated. In addition, data from their vaccination certificates and pregnancy passports were evaluated.

Results Overall, the records of only $19.5 \%$ of the pregnant women showed that they had been vaccinated against influenza in pregnancy. Among the group of pregnant women who had a previous history of vaccinations against influenza the willingness to be vaccinated was high (43.3\%) and this figure was statistically significant. The vaccination rate was even higher (49.9\%) and even more statistically significant among pregnant women whose gynecologist or family physician had recommended that they should be vaccinated. In contrast, only $3.3 \%$ of pregnant women who had not been given the recommendation to vaccinate by their physicians were vaccinated against influenza. Discussion The failure to recommend that pregnant women be vaccinated against influenza and women's lack of any previous experience of influenza vaccination were the main reasons for the inadequate influenza vaccination coverage in pregnancy.

Conclusion One of the key points to increase the influenza vaccination rate is to intensify the counselling of the pregnant women through the gynecologist.

\section{ZUSAMMENFASSUNG}

Einleitung In Deutschland werden die Impfempfehlungen jährlich von der Ständigen Impfkommission am Robert Koch-Institut (= STIKO) überarbeitet und veröffentlicht. Im Jahre 2010 wurde die Impfempfehlung dahin gehend geändert, dass nun schwangere Frauen ab dem 2. Trimenon und solche mit zusätzlicher Grunderkrankung bereits ab dem 1. Trimenon die Impfung gegen saisonale Influenza erhalten sollten. Diese Arbeit beschäftigt sich mit der Impfquote und den Faktoren, die diese beeinflussen.

Methode Hierzu wurde in den beiden Influenzasaisons 2012/2013 und 2013/2014 eine Querschnittsstudie an 2 Level-1-Perinatalzentren in 2 verschiedenen Bundesländern (Saarland und Rheinland-Pfalz) mit insgesamt 253 schwangeren Frauen durchgeführt. Schwangere wurden mittels standardisiertem und vorgetestetem Fragebogen bezüglich ihres Kenntnisstands zur Impfempfehlung der saisonalen Influenza und eventueller, die Impfentscheidung beeinflussender Faktoren be- 
fragt. Weiterhin wurden Daten aus dem Impfpass und dem Mutterpass ausgewertet.

Ergebnisse Insgesamt war bei 19,5\% der Graviden eine Influenzaimpfung in der Schwangerschaft angegeben. Eine signifikant hohe Influenza-Impfbereitschaft zeigte sich mit $43,3 \%$ in der Gruppe der Schwangeren, die bereits vor der Schwangerschaft Influenzaimpfungen erhalten hatten. Eine noch höhere und auch signifikante Impfquote fand sich mit $49,4 \%$ bei den Schwangeren, die diese Impfung durch ihren Frauen- oder Hausarzt empfohlen bekommen haben. Im Gegen- satz dazu waren nur 3,3\% der Graviden gegen Influenza geimpft, die diese Empfehlung nicht durch ihren Arzt erhalten haben.

Diskussion Die ungenügende Anwendung der Empfehlung zur Influenza-Schutzimpfung bei Schwangeren sowie die mangelnde Vorerfahrung der Graviden mit dieser Impfung sind Hauptgründe für eine mangelnde Impfbereitschaft gegen Influenza in der Schwangerschaft.

Schlussfolgerung Einer der Hauptpunkte um die Influenzaimpfrate zu erhöhen, besteht in der Beratungsintensivierung der Schwangeren durch die Gynäkologen.

\section{Introduction}

In Germany vaccination recommendations are revised annually and published by the Standing Committee on Vaccination at the Robert Koch Institute (STIKO) [1]. The STIKO vaccination recommendations published in 2010 were expanded to include the recommendation that pregnant women in the 2 nd trimester of pregnancy should also be vaccinated against seasonal influenza. The recommendations stated that pregnant women with additional underlying disease should already be vaccinated in the 1 st trimester of pregnancy [2]. As the influenza vaccine is an inactivated vaccine, pregnant women can be vaccinated at any stage during pregnancy. The rationale behind the STIKO recommendation to only vaccinate healthy pregnant women in the 2 nd trimester of their pregnancy is based on the fact that spontaneous abortions are relatively common in the 1 st trimester of pregnancy and STIKO does not want to create any association between these spontaneous abortions and the influenza vaccination [3].

Most of the studies on the morbidity, mortality and course of disease in pregnant women who had influenza were carried out during the influenza pandemics of 1918, 1957 and 2009. While pregnant women are not more likely to contract influenza than non-pregnant persons, if they do come down with influenza pregnant women are significantly more likely to require hospitalization because they have a higher risk of developing influenza-associated complications [4-9]. Compared to the normal population, the risk of hospitalization for pregnant women during the H1N1 pandemic of 2009 in the USA was $0.32 / 100000$ pregnant women compared to just 0.08 per 100000 persons in the normal population. The risk of requiring hospitalization for influenza $A$ (H1N1) was therefore 4 times higher for pregnant women compared to the normal population [7]. Moreover, pregnant women with influenza have a significantly increased risk of miscarriage or preterm delivery, although detailed data have only been collected during influenza pandemics [6-11]. Several studies have shown that maternal influenza infection during pregnancy is not only associated with an increased risk of spontaneous abortion but also with an increased risk of preterm delivery, low birth weight, a high rate of small for gestational age (SGA) infants, and higher rates of fetal mortality [8-18].

During the pandemic of 1918 in the USA and the United Kingdom it was found that pregnant women had higher rates of secondary pneumonia and higher mortality rates compared to the normal population [19-21]. A higher mortality rate for pregnant women compared to non-pregnant women of child-bearing age was also recorded during pandemic of 1957 [22, 23].

During these two influenza pandemics, $50 \%$ of pregnant women with influenza developed pneumonia which was associated with a maternal mortality rate of $50 \%$ and an overall rate of lost pregnancies of 52\% [24-26]. The percentage of pregnant women among the influenza-related deaths registered for the 2009 influenza $A$ infection in the USA was $5 \%$. The mortality rate for pregnant women who required intensive medical care was $20 \%$. Of these women, $8.9 \%$ were in the 1 st trimester, $26.8 \%$ in the 2 nd trimester and $64.3 \%$ in the 3rd trimester of pregnancy [27].

Kelly et al. calculated a relative risk of dying from an $\mathrm{H} 1 \mathrm{~N} 1$ influenza infection of 1.4 for pregnant women compared to the normal population [28].

The reported mortality figures for pregnant women who were hospitalized because of an influenza infection range between 3.6 and $20 \%$ [27, 29-31].

Based on two meta-analyses it has been calculated that pregnant women had a relative risk of 6.8 (95\% confidence interval [CI]: 4.5-12.3) for being hospitalized, i.e. a significantly increased risk of being admitted to hospital as an in-patient, compared to non-pregnant women who had an odds ratio (OR) of 2.44 (95\% Cl: 1.22-4.87) [32,33].

Another study reported an influenza-related morbidity rate resulting in hospitalization for pregnant women in their 3rd trimester of 2.5 per 1000 pregnant women in the last third of their pregnancies [34].

During the influenza seasons of 1998/1999 and 2001/2002, Cox et al. found a morbidity rate for respiratory diseases which led to hospitalization of the pregnant woman of 22.3/1000, which was double that reported for other periods of time outside the influenza season [35].

A study from Canada is one of the few studies which has investigated the hospitalization rates of pregnant women outside pandemics. The study was able to show that the hospitalization rate for pregnant women in the 3rd trimester of pregnancy was five times higher during the influenza season than that of non-pregnant women. It was also able to show that the hospitalization rate for pregnant women during the influenza season was more than double that of the rate outside the influenza season [36].

Vaccination against influenza during pregnancy is generally considered harmless as an inactivated vaccine is used for vaccination. There are no indications or evidence for any teratogenicity. In fact, some studies found that the complications described above decreased significantly following vaccination [8, 37-44]. Influenza 
vaccination also has a protective effect on the unborn child because of the transfer of maternal antibodies across the placenta [39-46]. These antibodies continue to circulate in the infant's bloodstream until around the 4th month of life and during this time they offer a certain level of protection against infections which the infantile immune system is not yet capable of providing [44].

The conclusion to be drawn from these facts is that vaccination against seasonal influenza can reduce the number of people who develop the infection and therefore also the number of pregnant women requiring in-patient care and the number of cases with serious infection requiring intensive care. For the unborn child, vaccination could bring benefits by potentially reducing the rate of preterm births and the number of births of SGA infants. Post partum, the transfer of maternal antibodies across the placenta to the fetus can provide the newborn with some protection against influenza. Thus, vaccination against seasonal influenza offers numerous benefits to pregnant women and their unborn and newborn children, and the risks associated with vaccination are contained.

Up to now there was not much data available in Germany on how the amendments to the vaccination recommendations of 2010 have been accepted by pregnant women.

Almost all of the data on influenza-related morbidity, mortality, and the course of illness in pregnant women go back to the influenza pandemics of 1918, 1957 and 2009.

Data on the seasonal influenza-related morbidity and mortality in pregnant women are not collected systematically in Germany. There is only an obligation to notify the authorities if laboratory testing has confirmed the presence of the influenza virus.

This study aimed to investigate the acceptance of influenza vaccination recommendations among pregnant women and to determine the influencing factors which encourage or mitigate against vaccination.

\section{Methods}

\section{Survey methods}

A study to determine the influenza vaccination status of pregnant women was carried out at the University Gynecological Hospital in Homburg/Saar from December 2012 to February 2014 and at the Gynecology Department of Worms Hospital from February 2013 to February 2014. All pregnant women presenting to either of these gynecology hospitals, whether to give birth or attend a prenatal clinic, were requested to complete a standardized, pretested questionnaire ( $\triangleright$ Fig. 1 ) and to bring their vaccination certificate along. During the main survey period, i.e. 2013, 1286 births were recorded for the hospital in Homburg/Saar and 1585 births for the hospital in Worms.

\section{Collected parameters}

The questionnaire was used to collect data on the pregnant woman's medical history, including any general illnesses or disorders such as cardiac disease, pulmonary or intestinal disorders, hypertension and diabetes. Questions were also asked about preeclampsia and infectious diseases. General information collected included the woman's profession and whether she did any sports before or during her pregnancy. In the questions focused specifi-
- Table 1 Data collected from pregnancy passports and vaccination certificates.

\begin{tabular}{l|l|}
\hline Pregnancy passport & Vaccination certificate \\
\hline - Weight prior to pregnancy & - Pneumococci \\
\hline - BMI & - Meningococci \\
\hline - Number of pregnancies & - Influenza; date \\
\hline - Pre-existing conditions & of the last vaccination \\
\hline - Familial medical history & - TB \\
\hline - New infections & - Yellow fever \\
\hline - Particular stresses & - Cholera \\
\hline - Multiple pregnancies & - Typhoid \\
\hline - Amniotic fluid & - HPV \\
\hline - Rubella immunity & - Tick-borne encephalitis \\
\hline - Chlamydia & - Rabies \\
\hline - Syphilis test carried out & - Japanese B encephalitis \\
\hline - HBsAg positive & - Smallpox \\
\hline
\end{tabular}

cally on vaccination status, women were asked whether they had had any vaccinations during the pregnancy, in particular any influenza vaccinations during or prior to the pregnancy and who had recommended that they should be vaccinated against influenza. Women were also asked about any prior negative experiences with the influenza vaccination.

The questionnaire also included an open question on potential reasons for having refused to be vaccinated against influenza.

Data were also obtained from women's pregnancy passports and vaccination certificates after receiving prior permission from the women in writing ( $\triangleright$ Table 1 ).

Women were asked about their age, BMI, number of pregnancies, whether they did sports, whether they had been given the recommendation to be vaccinated against influenza, about their previous illnesses, whether they had been vaccinated against influenza before becoming pregnant, whether they had had a nuchal scan, what their profession was, and whether they worked in the healthcare sector, as these were considered factors which could potentially influence the decision to be vaccinated against influenza.

To investigate whether women with a higher BMI were more likely to be advised to vaccinate against influenza, the women were divided into 2 groups based on WHO criteria [47]. Women with a BMI (body mass index) of up to $24.99 \mathrm{~kg} / \mathrm{m}^{2}$ were classified as normal weight and women with a BMI of $25.00 \mathrm{~kg} / \mathrm{m}^{2}$ and above were classified as overweight.

\section{Description of the study population}

A total of 187 women who attended the University Gynecological Hospital in Homburg/Saar and 66 women who attended the Gynecology Department of Worms Hospital were included in the study, resulting in an overall study population of 253 pregnant women. Of these 253 pregnant women, 236 women (93.28\%) provided at least one useable statement about their seasonal influenza vaccination status. On 17 questionnaires, the question whether the respondent had been vaccinated against influenza was not answered. 


\begin{tabular}{l} 
Surname: \\
\hline Date of birth: \\
\hline Profession: \\
\hline
\end{tabular}

\section{First name:}

Place of birth:

Nationality:

NT (nuchal translucency) scan carried out:

Yes

Existing medical conditions (e.g. heart, lung, bowel condition, etc.):

Hypertension (= high blood pressure):

High blood pressure already present prior to pregnancy:

$\square$ Yes $\quad \square$ No

Diabetes:

Yes

Diabetes already present prior to pregnancy:

$\square$ Yes $\square$ No

Preeclampsia:

Yes

$\square$ No

Infectious disease (blood-borne):

$\square$ Yes

State which disease:

Sports before or during pregnancy (at least $2 \times 30 \mathrm{~min} /$ week):

Yes

Any vaccinations during pregnancy (also in previous pregnancies):

Were you informed about being vaccinated against influenza during the course of this pregnancy by your gynecologist, general practitioner or someone else:

$\begin{array}{ll}\square \text { Yes } & \square \text { No } \\ \square \text { Yes } & \square \text { No } \\ \square \text { Yes } & \square \text { No }\end{array}$
By gynecologist
By general practitioner
By .

Do you intend to be vaccinated against influenza during this pregnancy:

Yes $\square$ No

If not, what are your reasons for not being vaccinated against influenza:

(For example: reservations about safety of vaccine, medically contraindicated, do not consider influenza dangerous, etc.)

Have you been vaccinated against influenza when you were not pregnant:

How often:

If yes, side-effects or experience with the influenza vaccination:

(For example: reaction at the injection site, discomfort/feeling unwell, fever, etc.)

- Fig. 1 Questionnaire used to collect data on factors affecting vaccination status.

The study focused on finding out more about the influenza vaccination status of pregnant women and the factors which could influence the decision for or against vaccination. The decision on vaccination and vaccination recommendations were then correlated with the investigated parameters.

Patients were repeatedly unable to answer individual questions on the questionnaire. The missing data for individual parameters was subsequently deducted from the analysis of the overall number of samples. The percentages therefore always refer to the respective amended total number.

\section{Statistical analysis}

Statistical analysis was done using the statistics program IBM ${ }^{\circledR}$ SPSS $^{\circledR}$ Statistics 21.0. Statistical tests used for analysis included the Kolmogorov-Smirnov test, Mann-Whitney U-test, Fisher's exact test and the $x^{2}$-test. The Kolmogorov-Smirnov test was used to test whether variables were normally distributed. Mann-Whitney U-test was used to compare two groups by detecting differences in the distributions of continuous variables; Fisher's exact test and the $x^{2}$-test were used to compare the distribution of nominal variables of two groups. Results were considered statistically significant when $\mathrm{p}<0.05$.

Ethics vote number: $144 / 14$ 


\section{Results}

\section{Influenza vaccination during pregnancy}

Out of the total patient population treated at both hospitals ( $n=236$ women), the records showed that only 46 women (19.5\%) had been vaccinated against influenza in pregnancy.

When the groups were studied in more detail, the patient cohort from the Rhineland-Palatinate (i.e. Worms) showed a significantly higher willingness to be vaccinated $(28.6 \%)$ than the cohort from the Saarland (i.e. Homburg) with $16.2 \%$.

\section{Normal distribution}

Kolmogorov-Smirnov test was used to test whether sample data were normally distributed for the total patient population and the respective subgroups. Graphically, the probability density of normal distribution is depicted as a Gaussian curve. The standard deviation (SD) indicates the percentage of values around the mean. - Fig. 2 shows the typical representation of a normal distribution, in this case for the age of the women in the overall patient population $(n=253)$.

The parameters "age", "BMI" and "number of pregnancies" were all normally distributed. The mean and standard deviation for these three variables in the overall patient population are given in $>$ Table 2. The other parameters were surveyed using yes-no questions which, of course, only permitted yes-no answers.

\section{Association between age and influenza vaccination}

The mean age of the normally distributed overall patient population with 253 participants was 31.34 years $(S D=4.7)$. The age distribution of these pregnant women showed that the cohort of pregnant women who had opted to be vaccinated against influenza $(n=46)$ had a mean age of 32.6 years $(S D=4.5)$ while the pregnant women who refused vaccination $(n=190)$ were on average 30.9 years old $(S D=4.5)$. There was therefore no significant difference $(p=0.6)$ between groups for the overall study population of women who reported their vaccination status ( $n=236$; mean age: 31.2 years; $S D=4.6)$.

While there was no significant difference in the mean ages of pregnant women who accepted and the pregnant women who rejected vaccination in the Homburg cohort $(p=0.47)$, the difference in mean age between the two groups in the Worms cohort was significant $(p=0.01)$. In Worms the mean age of the women who were vaccinated against influenza was higher at 32.8 years $(S D=4.8)$ compared to a mean age of 29.2 years $(S D=4.4)$ for the pregnant women who rejected influenza vaccination.

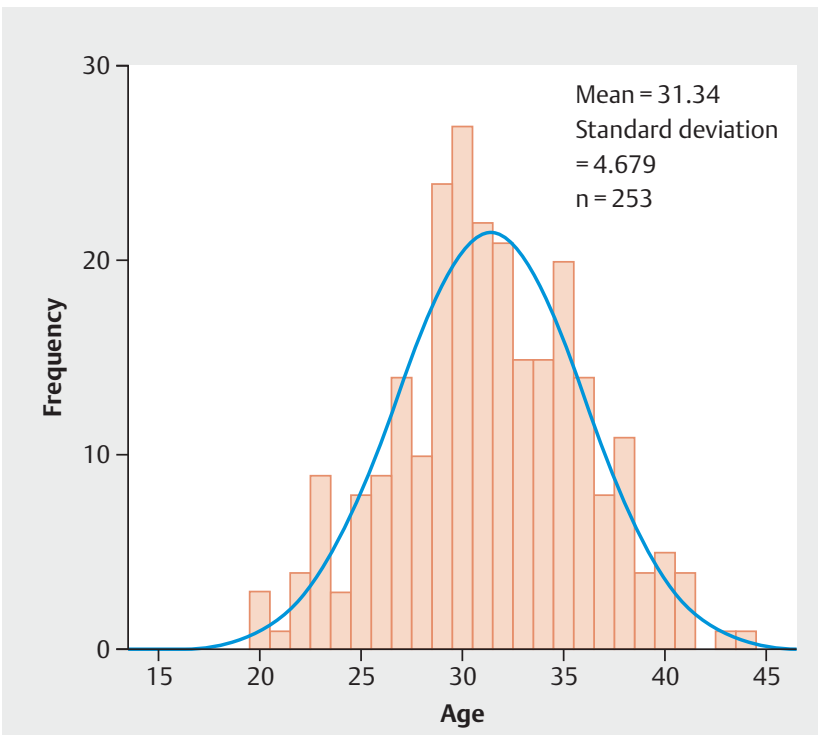

- Fig. 2 Graph showing normal distribution of the variable "age" for the total patient population $(n=253)$.

\section{Association between pregnancy and documented influenza vaccination}

$52.9 \%(n=99)$ of the surveyed women were pregnant for the first time. In the total patient population it was found that the percentage of multiparae who were vaccinated against influenza during pregnancy was higher with $21.7 \%(n=18)$ compared to the percentage of primiparae $(14.1 \% ; n=13)$. The trend was not statistically significant $(p=0.135)$.

\section{Association between BMI (body mass index) and influenza vaccination}

No significant association was found between BMI and vaccination coverage either in the total patient population $(n=107)$ or in the subgroups. In all patient cohorts it was found that more women with a higher BMI chose to be vaccinated against influenza. The mean BMI of vaccinated women in the total patient population ( $n=17$ ) was $27.1 \mathrm{~kg} / \mathrm{m}^{2}(\mathrm{SD}=7.8)$ compared to a BMl of $24.2 \mathrm{~kg} /$ $\mathrm{m}^{2}(\mathrm{SD}=4.6)$ for women who did not choose to be vaccinated $(n=90 ; p=0.099)$.

- Table 2 Parameters with normal distribution.

\begin{tabular}{|l|l|l|l|}
\hline Parameter & Total study population (n) & Mean & Standard deviation \\
\hline Age & 253 & 31.34 & 4.679 \\
\hline BMI & 117 & 24.54 & 5.089 \\
\hline Number of pregnancies & 187 & 1.75 & 1.013 \\
\hline
\end{tabular}




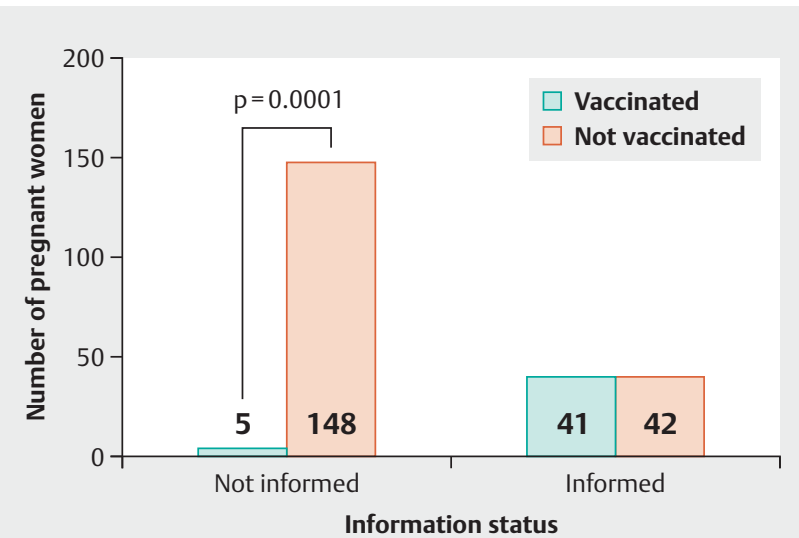

- Fig. 3 Information status and influenza vaccination for the total patient population $(n=236)$.

\section{Association between BMI and influenza vaccination recommendation}

To investigate whether women with a higher BMI were more likely to have received the recommendation to vaccinate against influenza, the patient population was divided into 2 groups. One group consisted of women who were of normal weight or underweight (BMI $\left.\leq 24.99 \mathrm{~kg} / \mathrm{m}^{2}\right)$; the other group consisted of women who were overweight $\left(\mathrm{BMI}>25.00 \mathrm{~kg} / \mathrm{m}^{2}\right)$. Out of the total patient population of women for whom a BMI was calculated $(n=117), 63.25 \%(n=74)$ had a normal weight or were underweight and $36.75 \%(n=43)$ were considered overweight according to the WHO definition. For 49 of these pregnant women, the records showed that vaccination had been recommended. For the subgroups this meant that 29 of the normal weight or underweight women and 20 of the overweight women had received the recommendation to be vaccinated against influenza during pregnancy. Given as a percentage, this means that $39.19 \%$ of normal weight or underweight women and $46.51 \%$ of overweight women had been given a recommendation by their physician or midwife to be vaccinated against influenza during pregnancy. The difference between groups was not significant $(p=0.13)$.

\section{Association between receiving a vaccination recom- mendation and recorded influenza vaccination}

A total of 157 (65.4\%) out of 240 women from the total patient population who stated whether or not they had received the recommendation to be vaccinated against influenza reported that they had not been informed about the possibility of being vaccinated against influenza.

Of the 83 women (34.6\%) who had been informed about the possibility of being vaccinated against influenza, $28.3 \%(n=68)$ were told about it by their gynecologist and $1.7 \%(n=4)$ were given the recommendation to be vaccinated by both their gynecologist and their family practitioner. $2.5 \%(n=6)$ of pregnant women were only informed about the possibility of being vaccinated against influenza by their family practitioner.

$2.1 \%(n=5)$ of informed pregnant women obtained the information about the possibility of being vaccinated against influenza from other sources such as the company physician or the physicians and midwives at the hospital.

When the subgroups were studied, significant differences in information status were found between the two surveyed locations. While $27.8 \%(n=49)$ of patients in the Homburg group were informed about the option of being vaccinated against influenza, the percentage in the Worms group was $53.1 \%(n=34)$. The most important source of information for women in both study populations were their gynecologists. - Table 3 shows the sources of information and their distribution for both surveyed locations.

To show the impact of an explicit recommendation to get vaccinated, the pregnant women were divided into two groups: "informed" vs. "not informed". All pregnant women who had not been given the recommendation to be vaccinated, including those women who had sought out the information themselves, were grouped into the latter cohort.

As $>$ Fig. 3 shows, $49.4 \%(n=41)$ of women who were given the vaccination recommendation actually subsequently went on to be vaccinated against influenza. Only $3.3 \%$ of pregnant women $(n=5)$ who had not received a vaccination recommendation opted for vaccination. The difference between these two groups was statistically highly significant $(p=0.0001)$.

This high level of significance continued for the subgroups in Homburg and Worms ( $p=0.0001$ for both groups).

One disparity between the two subgroups was found for the group of "not-informed" women; 5 of the "not-informed" women in the Homburg cohort (4.0\%) opted independently to be vacci-

- Table 3 Source of vaccination information/recommendation for the subgroups from Homburg and Worms.

\begin{tabular}{|l|c|c|c|c|}
\hline Recommendation & Number (HOM) & Percentage (HOM) & Number (WO) & Percentage (WO) \\
\hline No recommendation given & 127 & 72.2 & 30 & 46.9 \\
\hline Recommended by family practitioner (GP) & 4 & 2.3 & 2 & 3.1 \\
\hline Recommended by others & 4 & 2.3 & 1 & 1.6 \\
\hline Recommended by gynecologist (GYN) & 38 & 21.6 & 30 & 46.9 \\
\hline Recommended by GP and GYN & 3 & 1.7 & 1 & 1.6 \\
\hline Total & 176 & 100 & 64 & 100 \\
\hline
\end{tabular}




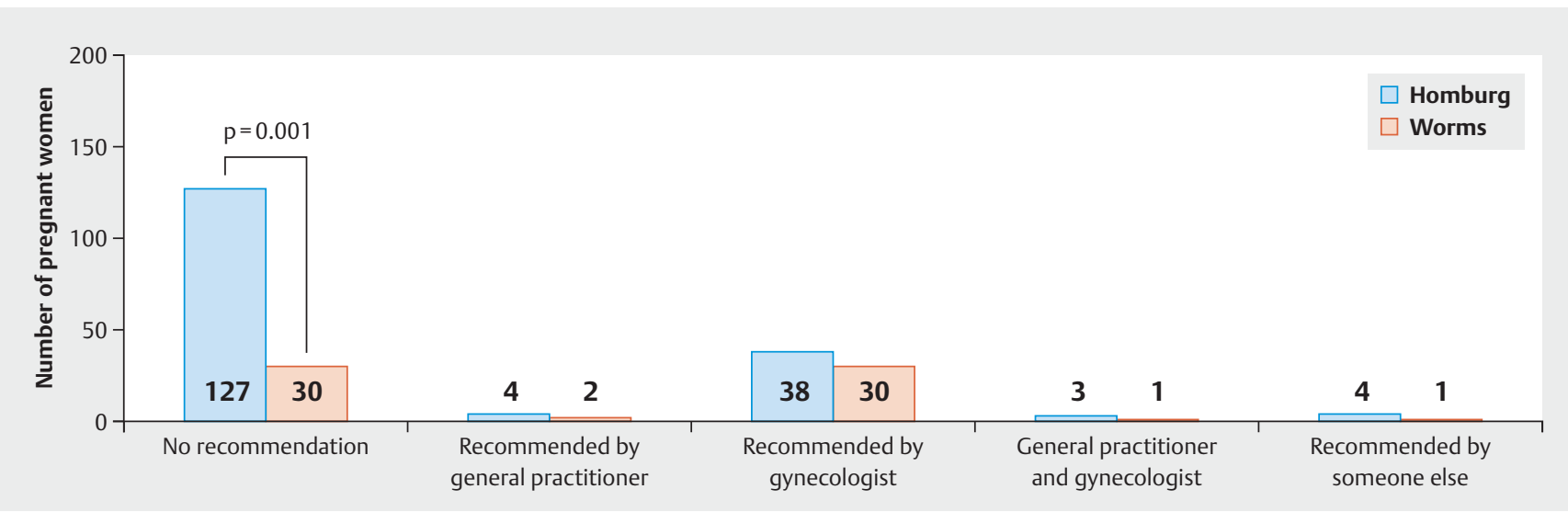

- Fig. 4 Vaccination recommendation and implementation for the total patient population (Homburg $n=176$; Worms $n=64$ ).

nated while none of the "not informed" pregnant women in the Worms cohort chose to be vaccinated.

- Fig. 4 shows that women who were given the recommendation to be vaccinated against influenza in pregnancy, were significantly more likely to be vaccinated $(p=0.001)$, particularly if the recommendation was given by their gynecologist.

\section{Association between previous influenza vaccination and influenza vaccination in pregnancy}

Data on prior vaccinations obtained from vaccination certificates was available for a total of 229 pregnant women. - Table $\mathbf{4}$ shows how many of the surveyed women were vaccinated against influenza and how often they had been vaccinated against influenza before they were pregnant.

To investigate the association between being vaccinated against influenza prior to pregnancy and choosing to vaccinate during pregnancy, the total patient population was divided into two groups: a "prior vaccination-yes" and a "prior vaccinationno" group.

Analysis showed a highly significant association between the number of influenza vaccinations before pregnancy and the decision to be vaccinated against influenza during pregnancy $(p=0.0001)$. Of the 66 women who had had at least one influenza vaccination before their pregnancy, 26 women (43.3\%) also requested an influenza vaccination during their pregnancy. In contrast, only 17 (11.0\%) of the 154 women who had never had a previous influenza vaccination were vaccinated during pregnancy. When the two locations were analyzed separately, the differences between the group of women who had had prior vaccinations and the group which had not were also significant at both locations ( $p=0.0001$ Homburg group; $p=0.003$ Worms group).

- Table 5 lists the most common objections to the influenza vaccination cited by pregnant women in the open part of the survey.

Two main types of arguments emerged. In one line of argumentation, the risk of developing influenza and the associated danger were underestimated; the other line of argumentation was that pregnant women considered the vaccine too risky.
- Table 4 Recorded number of previous vaccinations for the total patient population.

\begin{tabular}{|l|c|c|}
\hline $\begin{array}{l}\text { Number of previous } \\
\text { vaccinations }\end{array}$ & Number (n) & Percentage \\
\hline 0 & 163 & 71.2 \\
\hline 1 & 29 & 12.7 \\
\hline 2 & 14 & 6.1 \\
\hline 3 & 6 & 2.6 \\
\hline 4 & 9 & 3.9 \\
\hline 5 & 3 & 1.3 \\
\hline 6 & 4 & 1.7 \\
\hline 7 & 0 & 0 \\
\hline 8 & 1 & 0.4 \\
\hline Total & 229 & 100 \\
\hline
\end{tabular}

\section{Discussion}

The main difficulty when carrying out this study was that while many pregnant women completed the questionnaire, many of them could not find their vaccination certificate. This meant that it was difficult to objectively verify the data provided by the women regarding their vaccination behavior.

For the target groups for whom the STIKO recommends seasonal influenza vaccination, the goal is to achieve a vaccination coverage of at least $75 \%$ based on the guidelines of the World Health Organization (WHO). However, this is not currently achieved for any of the target groups in Germany $[48,49]$. Other countries have also not managed to achieve the WHO target. The figures on vaccination behavior vary greatly between countries. Thus, for the influenza season of $2011 / 2012$, the percentage of pregnant women vaccinated against influenza was $2 \%$ in Slovenia and $47 \%$ in the USA $[50,56,57]$. The causes for this are many and varied. They range from the differences between systems provid- 
- Table 5 Reasons cited against being vaccinated against influenza during pregnancy.

\begin{tabular}{|c|c|c|}
\hline Risk of influenza is underestimated & Vaccine considered too risky & Various other counterarguments \\
\hline $\begin{array}{l}\text { - Influenza is not dangerous } \\
\text { - Risk of being infected with influenza is low } \\
\text { - Not needed } \\
\text { - Not at risk of contracting influenza } \\
\text { - Influenza season has passed } \\
\text { - Infant will be borne in summer } \\
\text { - Have not had influenza at other times either } \\
\text { - Rarely ill } \\
\text { - Never had influenza } \\
\text { - Low risk of infection } \\
\text { - No reason to be vaccinated } \\
\text { - Not a high-risk group } \\
\text { - Influenza vaccination is unnecessary } \\
\text { - Not relevant } \\
\text { - Not afraid of infection } \\
\text { - Good immune system }\end{array}$ & $\begin{array}{l}\text { - Vaccination is too dangerous } \\
\text { - Ran a temperature as a side-effect } \\
\text { following a previous vaccination } \\
\text { - Vaccinations make you ill } \\
\text { - Reservations because of the pregnancy } \\
\text { - Generally opposed to vaccinations } \\
\text { - Fear of side-effects } \\
\text { - Reservations about safety } \\
\text { - Dangerous for the infant } \\
\text { - Fear of complications } \\
\text { - Vaccinations are not safe } \\
\text { - Fear of risks and side-effects } \\
\text { - Doubts about the efficacy } \\
\text { of the vaccination } \\
\text { - Afraid of side-effects because of } \\
\text { - } \text { - Reservations Mecause of the safety } \\
\text { of the vaccine and its impact } \\
\text { - Never been vaccinated against influenza } \\
\text { before } \\
\text { - Afraid of side-effects } \\
\text { - Intolerance } \\
\text { - Afraid for the infant } \\
\text { - Bad experiences } \\
\text { - Unnecessary influence on the infant }\end{array}$ & $\begin{array}{l}\text { - High-risk pregnancy } \\
\text { - It is not the influenza season } \\
\text { - Because of underlying fibromyalgia } \\
\text { - Vasculitis } \\
\text { - Not interested } \\
\text { - Never thought of it } \\
\text { - Afraid of injections } \\
\text { - Multiple sclerosis } \\
\text { - Do not get vaccinated against } \\
\text { - other pathogens either } \\
\text { - Was not informed about it } \\
\text { - Pointless } \\
\text { - Had a cold } \\
\text { - Missed the right time } \\
\text { - Never ill } \\
\text { - Partner does not consider it necessary } \\
\text { - Never thought about it } \\
\text { - Almost completed pregnancy } \\
\text { - Not during pregnancy } \\
\text { - Medically contraindicated } \\
\text { - Refused } \\
\text { - Prefer to be cautious } \\
\text { - Never had it before } \\
\text { - Undecided } \\
\text { - No vaccination even outside the pregnancy } \\
\text { - Do not get ill easily } \\
\text { - Because of my Crohn's disease }\end{array}$ \\
\hline
\end{tabular}

ing information to different forms of financing the vaccinations and to differences in the time points recommended for vaccinating pregnant women.

If you look at the average vaccination rates for the different target groups listed by the STIKO during the seasons 2007/2008 to $2010 / 2011$, on average $26 \%$ of medical staff, $52 \%$ of persons over 60 years of age and $42 \%$ of chronically sick persons were vaccinated against seasonal influenza [51]. Compared to the national average in Germany, the federal states of the Saarland and the Rhineland-Palatinate made a particularly poor showing. In the season $2007 / 2008$ less than $50 \%$ (Saarland) and less than $40 \%$ (Rhineland-Palatinate) of persons aged 60 and above were vaccinated [52]. No reasons why vaccination rates are lowest in the Rhineland-Palatine and the Saarland could be found in the literature.

Compared to these rates, the vaccination rates of pregnant women in our study were significantly lower at $19.5 \%$. But this vaccination coverage corresponds to the data reported by Bödecker et al. In a national survey of 1025 pregnant women conducted across Germany in the period between February and March 2013, i.e., over a shorter time period but around the same time of year, the influenza vaccination rate was $23 \%$ [53]. As this finding was from a national survey, this suggests that the vaccination rate we found in the two German federal states is not an unusually low outlier but instead mirrors the average coverage across Germany. This means that a particularly low vaccination rate is not a regional issue but more likely to be a collective problem.
The recommendation to vaccinate pregnant women with chronic underlying disease against influenza has existed in the USA since 1966. In 1995 the influenza vaccination was recommended for all pregnant women in the third trimester of pregnancy, from 1997 it was also recommended to women in the second trimester of pregnancy and finally, from 2004, it was recommended for all pregnant women [54-57].

The recommendations to vaccinate pregnant women against influenza in the USA are therefore quite different to those in Germany. With vaccinations considered part of standard prenatal care, the vaccination rates between 2009 and 2013 in the USA ranged from 47.1 to $50.5 \%$ [55, 58, 59]. This vaccination coverage is more than double the vaccination rates found in our patient population. When looking at the potential factors which can influence patient behavior in the context of influenza vaccinations, there was a slight but not significant trend with respect to age and body mass index whereby older pregnant women and women with a higher body mass index were more likely to opt for vaccination. One potential explanation could be that overweight women are more aware of their increased risk of cardiovascular disease and of pregnancy-related co-morbidities and therefore they make an effort to minimize other potential risk factors where possible $[60,61]$. This awareness of their increased risk does not only appear to play a role for the affected women themselves, it also appears to influence their physicians and midwives. The data showed that overweight pregnant women were slightly more likely to be given the recommendation to be vaccinated against 
influenza, although the difference to the group of normal-weight women was not significant.

The trend with regard to age is consistent with the fact that women who have had one or more previous pregnancies are more likely to opt to be vaccinated against influenza during their current pregnancy. This is also congruent with the fact that primiparae are on average younger than multiparae.

If a woman chose to be vaccinated against influenza before she was pregnant, the probability that she would choose to be vaccinated during pregnancy was significantly higher at $43.3 \%$ compared to $11 \%$ of women who had not been previously vaccinated but chose to be vaccinated against influenza when they were pregnant.

One reason for this could be that pregnant women who had not been previously vaccinated against influenza lacked any experience of the vaccination. In contrast, when women who had previously been vaccinated against influenza became pregnant, they were able to refer to their own prior experience of vaccination. Moreover, it should also be noted that primiparae were less likely to vaccinate against influenza during pregnancy with a vaccination rate of $14.1 \%$, compared to multiparae who had a vaccination rate of $21.7 \%$. The difference was not statistically significant but could be explained by the fact that a woman for whom pregnancy constitutes an entirely new experience might try to avoid any risks, even if it is only a subjectively perceived risk.

Extensive dissemination of information is the best way of reducing such subjective fears. This was borne out by the fact that if the pregnant woman's general practitioner or gynecologist explicitly recommended that she should be vaccinated against influenza during her pregnancy, the recommendation correlated very significantly with an increase in vaccination rates. Out of a total of 83 women who were given the recommendation to be vaccinated, 41 women went on to be vaccinated. In contrast, only 5 of the 157 women who did not receive a recommendation to be vaccinated went of their own accord to be vaccinated against influenza during their pregnancy. In the study carried out in Germany by Bödeker et al. referred to above, mistrust was the main reason cited by pregnant women why they did not opt to be vaccinated [53]. Other reasons included a lack of awareness of the importance of being vaccinated against influenza and the lack of any official recommendation for vaccination. These findings correspond with our results. As $>$ Table 5 shows, the two main reasons which mitigated against being vaccinated against influenza in pregnancy were that the risk of an influenza infection was seriously underestimated and that the vaccine was considered too dangerous during pregnancy.

Numerous other studies have also reported that one of the arguments commonly voiced by pregnant women opposed to vaccination is their concern about the safety of the influenza vaccine [62-66].

The influence of treating physicians on the vaccination behavior of pregnant women has already been identified as a significant factor affecting vaccination coverage [67]. Honkanen et al. (1996) came to the conclusion that the extensive information provided by physicians was the main reason for the high rate of influenza vaccinations among elderly patients in Finland [68]. In their study of the influenza seasons 2006/2007 and 2007/2008 in Germany,
Blank et al. were able to show that the recommendation by a physician to be vaccinated was one of the main reasons (with rates of 71 and $76.4 \%$, respectively) for people to choose to be vaccinated against seasonal influenza $[69,70]$, a finding which was confirmed by the survey of Wortberg et al. [71].

Studies from Australia and Hong Kong also came to the conclusion that the willingness to be vaccinated against influenza during pregnancy was not correlated with age but depended significantly on whether their physician recommended that they should be vaccinated [72-74].

Thus, the two main factors influencing the decision of pregnant women to be vaccinated during pregnancy were the woman's own experience of vaccination and the attitude of her treating physician. This is remarkable as information on the importance of influenza vaccination during pregnancy can be found on internet forums and in pregnancy guides $[75,76]$.

Nevertheless, only five of the patients surveyed in our study opted to be vaccinated on their own volition or based on their own research. Consequently, the treating physicians are the determining factor for vaccination coverage.

A survey carried out in Germany investigated the reasons why gynecologists in private practice did not recommend that their patients should be vaccinated against influenza in pregnancy. Of the persons surveyed $39.6 \%$ expressed security concerns about the unborn infant, followed by the excessive time and effort required to inform patients in details (30.2\%), as well as security concerns on the part of the pregnant woman (29.2\%).

This was followed by a number of counterarguments against vaccination, which included doubts about the benefits of the vaccination and complaints about the low remuneration $(24.0 \%$ respectively), while $16.7 \%$ stated that there was no need for vaccination [77].

These figures show that even in 2016 numerous physicians in private practice in Germany are not sufficiently informed about the safety and benefits of vaccinating against influenza in pregnancy.

The limitations of the study are that it was only carried out at two medical centers, meaning that the study's validity with regard to the general vaccination status of pregnant women across all of Germany is limited.

Another weakness of the study is that the pregnant women in the two centers were not surveyed during the same period of time. This could result in a distortion of the data. Such a distortion of data could also result from the fact that the survey was carried out both in winter and in summer, and the vaccination rate in winter differed from the vaccination rate in summer.

Nevertheless, the findings of the study by Bödeker et al. with regard to influenza vaccination coverage and the reservations cited against vaccination were comparable with the results found in our study [53].

To improve the findings of our study it would have been useful to have asked in which week of pregnancy the women were vaccinated or had received the recommendation to be vaccinated and in which week of pregnancy the patient was when she was given the questionnaire. It would also have been useful to record at what time of year the survey was carried out; to have classified the patients' level of education in more detail, and to have in- 
cluded socio-economic factors such as household income and nationality.

One of the strengths of the study is that it did not merely record the patients' subjective statement about influenza vaccination in pregnancy but also attempted to get objective facts by verifying the statement using the patients' vaccination certificate. However, verification of the patients' general vaccination status and their status with regard to the influenza vaccination based on their vaccination certificates proved to be difficult as a large number of pregnant women were no longer able to locate their vaccination certificates.

\section{Conclusions}

As treating physicians are clearly the most important professionals consulted by pregnant women on health issues, information campaigns targeting physicians in private practice could lead to substantially higher vaccination rates.

This increase in information should be directed first and foremost at gynecologists, as they are the main professionals consulted by pregnant women. But general practitioners and midwives should also be targeted in an information campaign, as they too are confronted with questions respecting vaccinations during pregnancy.

\section{Five Key Points}

- The documented influenza vaccination rate for the total study population of pregnant women was $19.5 \%$.

- The influenza vaccination rate is therefore far below the target rate of $75 \%$ proposed by the STIKO and the WHO.

- The willingness to be vaccinated against influenza is high among pregnant women who have previously been vaccinated against influenza before they became pregnant.

- The most important factor which affects vaccination coverage is the recommendation given to the pregnant woman by her treating physician.

- Vaccination coverage can be increased if physicians help to raise patients' awareness and provide information.

\section{Conflict of Interest}

The authors declare that they have no conflict of interest.

\section{References}

[1] Robert Koch-Institut (RKI), Ständige Impfkommission. Aufgaben und Methodik. 2013. Online: http://www.rki.de/DE/Content/Kommissionen/ STIKO/Aufgaben_Methoden/methoden_node.html; last access: 07.03 .2013

[2] Robert Koch-Institut (RKI). Epidemiologisches Bulletin 30/2010 (30)

[3] Robert Koch-Institut. Saisonale Influenzaimpfung: Häufig gestellte Fragen und Antworten. Online: http://www.rki.de/SharedDocs/FAQ/ Impfen/Influenza/faq_ges.html?nn=2375548; last access: 26.01.2017
[4] Doyle T], Goodin K, Hamilton J] et al. Maternal and neonatal outcomes among pregnant women with 2009 pandemic influenza $A(H 1 N 1)$ illness in Florida, 2009-2010: a population-based cohort study. PLoS One 2013; 8: e79040

[5] Knuf M. Influenzainfektion in der Gravidität. Gynäkologe 2011; 44: 593600

[6] Laibl VR, Sheffield JS. Influenza and pneumonia in pregnancy. Clin Perinatol 2005; 32: 727-738

[7] Jamieson DJ, Honein MA, Rasmussen SA et al. H1N1 2009 influenza virus infection during pregnancy in the USA. Lancet 2009; 374: 451-458

[8] Rasmussen SA, Jamieson DJ, Uyeki TM. Effects of influenza on pregnant women and infants. Am J Obstet Gynecol 2012; 207: S3-S8

[9] Ortiz JR, Englund JA, Neuzil KM. Influenza vaccine for pregnant women in resource-constrained countries: a review of the evidence to inform policy decisions. Vaccine 2011; 29: 4439-4452

[10] Haberg SE, Trogstad L, Gunnes N et al. Risk of fetal death after pandemic influenza infection or vaccination during pregnancy. N Engl J Med 2013; 368: 333-340

[11] Hardy JM, Azarowicz EN, Mannini A et al. The effect of Asian influenza on the outcome of pregnancy, Baltimore, 1957-1958. Am J Public Health Nations Health 1961; 51: 1182-1188

[12] Mosby LG, Rasmussen SA, Jamieson DJ. 2009 pandemic influenza A (H1N1) in pregnancy: a systematic review of the literature. Am J Obstet Gynecol 2011; 205: 10

[13] Harris JW. Influenza occurring in pregnant women. JAMA 1919; 72: 978

[14] Centers for Disease Control and Prevention (CDC). Maternal and infant outcomes among severely ill pregnant and postpartum women with 2009 pandemic influenza A (H1N1)-United States, April 2009-August 2010. MMWR Morb Mortal Wkly Rep 2011; 60: 1193-1196

[15] Bloom-Feshbach K, Simonsen L, Viboud C et al. Natality decline and miscarriages associated with the 1918 influenza pandemic: the Scandinavian and United States experiences. J Infect Dis 2011; 204: 1157-1164

[16] McNeil SA, Dodds LA, Fell DB et al. Effect of respiratory hospitalization during pregnancy on infant outcomes. Am J Obstet Gynecol 2011; 204 : S54-S57

[17] Mendez-Figueroa $\mathrm{H}$, Raker $\mathrm{C}$ et al. Neonatal characteristics and outcomes of pregnancies complicated by influenza infection during the 2009 pandemic. Am J Obstet Gynecol 2011; 204: S58-S63

[18] Yates L, Pierce M, Stephens S et al. Influenza A/H1N1v in pregnancy: an investigation of the characteristics and management of affected women and the relationship to pregnancy outcomes for mother and infant. Health Technol Assess 2010; 14: 109-182

[19] Bland PB. Influenza in its relation to pregnancy and labor. Am J Obstet Dis Women Child 1919; 79: 184-197

[20] Harris JW. Influenza occurring in pregnant women. JAMA 1919; 72: 978980

[21] Mortimer P. Influenza-related death rates for pregnant women. Emerging Infect Dis J 2006; 12: 1805-1806

[22] Freeman DW, Barno A. Deaths from Asian influenza associated with pregnancy. Am J Obstet Gynecol 1959; 78: 1172-1175

[23] DEATHS from Asian influenza, 1957; a report by the Public Health Laboratory Service based on records from hospital and public health laboratories. Br Med J 1958; 1: 915-919

[24] Kort BA, Cefalo RC, Baker VV. Fatal influenza A pneumonia in pregnancy. Am J Perinatol 1986; 3: 179-182

[25] Kirshon B, Faro S, Zurawin RK et al. Favourable outcome after amantadine and ribaviron in a pregnancy complicated by influenza pneumonia. J Reprod Med 1988; 33: 399-401

[26] Schoenbaum SC, Weinstein L. Respiratory infection in pregnancy. Clin Obstet Gynecol 1979; 22: 293-300 
[27] Siston AM, Rasmussen SA, Honein MA et al. Pandemic 2009 influenza A (H1N1) virus illness among pregnant women in the United States. JAMA 2010; 303: 1517-1525

[28] Kelly H, Mercer G, Cheng A. Quantifying the risk of pandemic influenza in pregnancy and indigenous people in Australia in 2009. Euro Surveill 2009; 14: pii: 19441

[29] ANZIC Influenza Investigators and Australasian Maternity Outcomes Surveillance System. Critical illness due to 2009 A/H1N1 influenza in pregnant and postpartum women: population based cohort study. BM] 2010; 340: $c 1279$

[30] Jain S, Kamimoto L, Bramley AM et al. Hospitalized patients with 2009 H1N1 influenza in the United States, April-June 2009. N Engl J Med 2009; 361: 1935-1944

[31] Donaldson LJ, Rutter PD, Ellis BM et al. Mortality from pandemic A/H1N1 2009 influenza in England: public health surveillance study. BMJ 2009; 339: b5213

[32] Van Kerkhove MD, Vandemaele KA, Shinde V et al. Risk factors for severe outcomes following 2009 influenza A (H1N1) infection: a global pooled analysis. PLoS Med 2011; 8: e1001053

[33] Mertz D, Geraci J, Winkup J et al. Pregnancy as a risk factor for severe outcomes from influenza virus infection: a systematic review and metaanalysis of observational studies. Vaccine 2017; 35: 521-528

[34] Neuzil KM, Reed GW, Mitchel EF et al. Impact of influenza on acute cardiopulmonary hospitalizations in pregnant women. Am J Epidemiol 1998; 148: 1094-1102

[35] Cox S, Posner SF, McPheeters M et al. Influenza and pregnant women: hospitalization burden, United States, 1998-2002. J Womens Health (Larchmt) 2006; 15: 891-893

[36] Dodds L, McNeil SA, Fell DB et al. Impact of influenza exposure on rates of hospital admissions and physician visits because of respiratory illness among pregnant women. CMAJ 2007; 176: 463-468

[37] Legge A, Dodds L, MacDonald NE et al. Rates and determinants of seasonal influenza vaccination in pregnancy and association with neonatal outcomes. CMAJ 2014; 186: E157-E164

[38] Mak TK, Mangtani P, Leese J et al. Influenza vaccination in pregnancy: current evidence and selected national policies. Lancet Infect Dis 2008; 8: 44-52

[39] Manske JM. Efficacy and effectiveness of maternal influenza vaccination during pregnancy: a review of the evidence. Matern Child Health J 2014; 18: 1599-1609

[40] Munoz FM. Safety of influenza vaccines in pregnant women. Am J Obstet Gynecol 2009; 207: S33-S37

[41] Munoz FM, Greisinger AJ, Wehmanen OA et al. Safety of influenza vaccination during pregnancy. Am J Obstet Gynecol 2005; 192: 1098-1106

[42] Omer SB, Goodman D, Steinhoff MC et al. Maternal influenza immunization and reduced likelihood of prematurity and small for gestational age births: a retrospective cohort study. PLoS Med 2011; 8: e1000441

[43] Skowronski DM, De Serres G. Is routine influenza immunization warranted in early pregnancy? Vaccine 2009; 27: 4754-4770

[44] Tamma PD, Ault KA, del Rio C et al. Safety of influenza vaccination during pregnancy. Am J Obstet Gynecol 2009; 201: 547-552

[45] Zaman K, Roy E, Arifeen SE et al. Effectiveness of maternal influenza immunization in mothers and infants. N Engl J Med 2008; 359: 1555-1564

[46] Eick AA, Uyeki TM, Klimov A et al. Maternal influenza vaccination and effect on influenza virus infection in young infants. Arch Pediatr Adolesc Med 2011; 165: 104-111

[47] WHO. BMI classification. Online: http://apps.who.int/bmi/index.jsp? introPage=intro_3.html; last access: 28.03.2017

[48] World Health Organization. Influenza vaccines - WHO position paper. Weekly Epidemiological Record 2005; 33: 279-287

[49] Poethko-Müller C, Schmitz R. Impfstatus von Erwachsenen in Deutschland. Bundesgesundheitsbl 2013; 56: 845-857
[50] O'Flanagan D, Cotter S, Mereckiene J. Seasonal influenza vaccination in EU/EEA, influenza season 2011-12. 2013. Online: http://venice.cineca. org/VENICE Seasonal Influenza 2011-12 1.0v.pdf; last access: 15. 11.2013

[51] Böhmer MM. Impfquoten, Impfverhalten und Impfakzeptanz bei Erwachsenen in Deutschland [Dissertation]. Berlin: FU-Berlin; 2013

[52] Robert Koch-Institut. GBE Kompakt - 1/2011 - Grippeschutzimpfung in Deutschland - Ergebnisse der Studie „Gesundheit in Deutschland aktuell“ (GEDA). 2009. Online: http://www.rki.de/DE/Content/ Gesundheitsmonitoring/Gesundheitsberichterstattung/GBE DownloadsK/2011_1_Grippeschutzimpfung.html?nn=2531734; last access: 03.02.2011

[53] Bödeker B, Walter D, Reiter S et al. Cross-sectional study on factors associated with influenza vaccine uptake and pertussis vaccination status among pregnant women in Germany. Vaccine 2014; 32: 4131-4139

[54] Advisory Committee on Immunization Practices (ACIP). Morbidity and mortality weekly report. Updated interim influenza vaccination recommendations. 2004-05 Influenza season. Online: http://www.cdc.gov/ mmwr/preview/mmwrhtml/mm5350a7.htm; last access: 16.03.2014

[55] The American College of Obstetricians and Gynecologists. Committee Opinion. (Replaces No. 305, November 2004). 2010; 468: 1-2

[56] Vanessen G, Palache A, Forleo E et al. Influenza vaccination in 2000: recommendations and vaccine use in 50 developed and rapidly developing countries. Vaccine 2003; 21: 1780-1785

[57] Kennedy ED, Ahluwalia IB, Ding $\mathrm{H}$ et al. Monitoring seasonal influenza vaccination coverage among pregnant women in the United States. Am | Obstet Gynecol 2012; 207: S9-S16

[58] Centers for Disease Control and Prevention (CDC). Influenza vaccination coverage among pregnant women - 29 Sates and New York City, 200910 season. MMWR Morb Mortal Wkly Rep 2012; 61: 113-118

[59] Centers for Disease Control and Prevention (CDC). Influenza vaccination coverage among pregnant women-United States, 2012-13 influenza season. MMWR Morb Mortal Wkly Rep 2013; 62: 787-792

[60] Cedergren MI. Maternal morbid obesity and the risk of adverse pregnancy outcome. Obstet Gynecol 2004; 103: 219-224

[61] Sebire NJ, Jolly M, Harris JP et al. Maternal obesity and pregnancy outcome: a study of 287,213 pregnancies in London. Int J Obes Relat Metab Disord 2001; 25: 1175-1182

[62] Eppes C, Wu A, You W et al. Barriers to influenza vaccination among pregnant women. Vaccine 2013; 31: 2874-2878

[63] Centers for Disease Control and Prevention (CDC). Influenza vaccination coverage among pregnant women: 2011-12 influenza season, United States. MMWR Morb Mortal Wkly Rep 2012; 61: 758-763

[64] Wiley KE, Massey PD, Cooper SC et al. Uptake of influenza vaccine by pregnant women: a cross-sectional survey. Med J Aust 2013; 198: 373 375

[65] Yudin MH, Salaripour M, Sgro MD. Pregnant women's knowledge of influenza and the use and safety of the influenza vaccine during pregnancy. J Obstet Gynaecol Can 2009; 31: 120-125

[66] Meyer C, Reiter S. [Vaccine opponents and sceptics. History, background, arguments, interaction]. Bundesgesundheitsblatt Gesundheitsforschung Gesundheitsschutz 2004; 47: 1182-1188

[67] Riegger A. Pressegespräch anlässlich des 4. Deutschen Influenza-Kongresses. Die Influenza - eine immer währende Bedrohung. Donnerstag, 27. September 2012

[68] Honkanen PO, Keistinen T, Kivela S. Factors associated with influenza vaccination coverage among the elderly: role of health care personnel. Public Health 1996; 110: 163-168

[69] Blank PR, Schwenkglenks M, Szucs TD. Influenza vaccination coverage rates in five European countries during season 2006/07 and trends over six consecutive seasons. BMC Public Health 2008; 8: 272 
[70] Blank PR, Schwenkglenks M, Szucs TD. Disparities in influenza vaccination coverage rates by target group in five European countries: trends over seven consecutive seasons. Infection 2009; 37: 390-400

[71] Wortberg S, Walter D, Knesebeck M et al. Niedergelassene Ärzte als Multiplikatoren der Influenzaimpfung bei älteren Menschen, chronisch Kranken und medizinischem Personal. Bundesgesundheitsbl 2009; 52: 945-952

[72] Maher L, Hope K, Torvaldsen S et al. Influenza vaccination during pregnancy: coverage rates and influencing factors in two urban districts in Sydney. Vaccine 2013; 31: 5557-5564

[73] Taksdal SE, Mak DB, Joyce $S$ et al. Predictors of uptake of influenza vaccination-a survey of pregnant women in Western Australia. Aust Fam Physician 2013; 42: 582-586
[74] Yuet Sheung Yuen C, Yee Tak Fong D, Lai Yin Lee I et al. Prevalence and predictors of maternal seasonal influenza vaccination in Hong Kong. Vaccine 2013; 31: 5281-5288

[75] eltern.de Schwangerschaft. Grippe-Impfung für werdende Mütter? Gesundheit \& Fitness - Eltern.de. Online: http://www.eltern.de/ schwangerschaft/gesundheit-und-fitness/schwangerschaftgrippe-impfung.html; last access: 16.03.2014

[76] Forum goFeminin. Grippeimpfung in der Schwangerschaft. 2009. Online: http://forum.gofeminin.de/forum/matern1/_f101941_matern1Grippeimpfung-in-der-Schwangerschaft.html; last access: 16.03.2014

[77] Bödeker B, Seefeld L, Buck S et al. [Implementation of seasonal influenza and human papillomavirus vaccination recommendations in gynecological practices in Germany]. Bundesgesundheitsblatt Gesundheitsforschung Gesundheitsschutz 2016; 59: 396-404 